\title{
El fenómeno de la belleza como construcción social en $E l$ prestigio de la belleza, de Piedad Bonnett
}

Fecha de recepción: 22 de enero de 2019

Fecha de aprobación: 29 de mayo de 2019

\section{Resumen}

El siguiente artículo presenta un análisis de la representación discursiva de la belleza, desde la terminología bajtiniana, que incluye el ideologema, la palabra autoritaria, la palabra intrínsecamente convincente, la polifonía y el dialogismo, en torno a la teoría literaria; además, expone, a su vez, algunos hallazgos que se dan en cuanto a las relaciones de poder, las ideologías y las cargas axiológicas que se entretejen alrededor del fenómeno de la belleza como concepción estética y construcción social en dos personajes de la novela autobiográfica colombiana: El prestigio de la belleza de Piedad Bonnett, publicada en 2010, en la que se percibe una representación de la belleza basada en el cuerpo y otra basada en el intelecto.

Palabras clave: dialogismo; ideologema; palabra autoritaria; palabra intrínsecamente convincente; polifonía.

Citar: González, J. (abril-junio de 2020). El fenómeno de la belleza como construcción social en El prestigio de la belleza, de Piedad Bonnett. La Palabra, (37), 15-26. dio $_{\text {https://doi.org/ 10.19053/01218530.n37.2020.8866 }}$

\section{Jéssica Ivón Renata González Rallón}

Doctoranda en Educación. Magíster en Semiótica por la Universidad Industrial de Santander, Colombia. Licenciada en Español y Literatura. Docente investigadora UIS del Grupo de Investigación Cultura y Narración (CUYNACO). Universidad Industrial de Santander. renatagrallon@hotmail.com

(Dhttps://orcid.org/0000-00030175-347X 


\title{
la palabra
}

\section{The Phenomenon of Beauty as A Social Construction in El prestigio de la belleza by Piedad Bonnett}

\begin{abstract}
This article presents an analysis of the discursive representation of beauty, from the Bajtinian terminology, which includes the ideologeme, the authoritarian word, the intrinsically convincing word, polyphony and dialogism, around the literary theory. In addition, this text exposes some findings relating to the power relations, ideologies and axiological burdens that are woven around the phenomenon of beauty as an aesthetic conception and social construction in two characters of the auto-biographic Colombian novel, The Prestige of Beauty, of piety Bonnett, published in 2010, and in which a representation of beauty is perceived with in two ways: the first one is based on the body and the second one is perceived on the intellect.
\end{abstract}

Keywords: Dialogism;Ideologeme;Authoritative Word; Compelling Intrinsically Word; Polyphony. 
La novela autobiográfica recurre a la ficción ineludiblemente al convertirse en un híbrido que comparte con otros géneros, o subgéneros, la escritura predominante en la primera persona gramatical del singular, hace uso de la memoria, los olvidos, la confesión y la ficción (Romera, J., 1981). En definitiva, la autoficción rompe el pacto autobiográfico al mezclarse indisolublemente con la ficción novelesca y aceptar la improbabilidad de un discurso veraz (Alberca, 1999, p. 155).

Según un estudio riguroso para la recopilación bibliográfica sobre diarios íntimos, memorias y autobiografías en Colombia, realizado por Patricia Londoño y Mario Jursich (1945, p. 146), se puede afirmar que dentro de los discursos autobiográficos colombianos más antiguos se hallan: Vida de la madre sor Josefa de la Concepción Castillo publicada en 1817, en Filadelfia por Charles Theodore Hart Palmer; en 1826 aparece Memoires du general Morillo, Comte du Cartagena de Pedro Morillo, publicadas en París; y, en año 1831 William Mahonney publica Memorias de un oficial de la Legión Británica en Londres. Sin embargo, una lista más reciente da cuenta de discursos autobiográficos como: Autobiografía de Tomás Carrasquilla, Memorias de un abanderado de José. María. Espinosa, Diario de Bucaramanga de Luis Perú de Lacroix, Diario de la independencia de José. María. Caballero, Memorias de Baldomero Sanín Cano, Mi vida de Sor Josefa de Castillo, Memorias infantiles de Eduardo Caballero Calderón, Memorias de Francisco de Paula Santander, Impresiones y recuerdos de Luciano Rivera y Garrido, Reminiscencias de Francisco Ortiz, Memorias de Agustín Codazzi, Mi gente de Alberto Lleras, Diario de Jorge Gaitán Durán, Historia de un alma de José María Samper, Crónica de mi propia vida de Carlos Lleras Restrepo, entre otras obras y autores destacados de la época de la colonia y la independencia colombiana.

Mediante la escogencia de la narrativa femenina, para este análisis, se busca implicar la voz afectada, ignorada, censurada o acallada que padece los rigores de la belleza. No gratuitamente, la novela es escrita por una mujer y el texto cuenta con una narradora en primera persona que cuenta, entre otras cosas, sobre sus tratos con la belleza, en la que denuncia los obstáculos que enfrenta una mujer al ser estigmatizada bajo el calificativo de fea y estar subyugada por el prestigio de la belleza.

La mujer al configurarse como principal afectada frente a los avances tecnológicos en la medicina cosmética, estética y quirúrgica, así como a la presión de los medios masivos que la impulsan y obligan a construir y reconstruir su imagen para agradar a los demás, ha decidido emprender caminos que conllevan a la reflexión, a la crítica y a la construcción de nuevas formas de aceptación de ella misma. Uno de esos caminos es el empoderamiento mediante la palabra. Tal como lo hace Piedad Bonnet mediante sus pequeños y grandes textos desde los cuales empieza a afirmar que la belleza, tal como la concibe comercialmente la sociedad, es enteramente inútil.

La autobiografía inicialmente, como género, se justifica a partir de lo político y religioso como sucede con la autobiografía religiosa de San Agustín Confesiones y el Libro de la Vida de Santa Teresa de Jesús. Posteriormente, la autobiografía como género literario ha sido abordada como una forma de narración que oscila entre la literatura y la historia desde el siglo XVI. Algunos escritores reconocidos por sus textos autobiográficos son: Benvenuto Cellini con Vida, Jean-Jacques Rousseau y su texto Confesiones, François René de Chateaubriand y su publicación Memorias de ultratumba, Stendhal (Marie-Henry Beyle) con Vida de Henry Brulard, José Zorrilla y su obra Recuerdos del tiempo viejo, Lev Nikolaievich Tolstoi con Infancia, adolescencia y juventud, André Gide y su obra Diario, Pablo Neruda y su texto autobiográfico Confieso que he vivido: Memorias y Para nacer 
he nacido, Rafael Alberti y La arboleda perdida, Jean-Paul Sartre con su obra Las palabras, Gabriel García Márquez y su texto Vivir para contarla, entre otros escritores. Sin embargo, más que autobiografía, la muestra para este análisis semiótico tiende más a la novela (con forma) autobiográfica o biografía falsa (Courtés, J., 1997).

\section{Acercamientos a la bajtino- logía en el corpus}

Partiendo de que el corpus de la investigación tiene una forma enunciada que concierne a la autobiografía novelesca, se hace imprescindible abordar algunos aspectos de la terminología bajtiniana en torno a la teoría literaria que ayuden a resolver no solo el problema de la representación discursiva de la belleza, sino que, permita hacer un acercamiento preciso alrededor de las cargas axiológicas, ideológicas y representacionales que giran en torno de la belleza.

A continuación, se presentarán algunos de los términos de la bajtinología que han sido clave para la comprensión, el análisis y el desarrollo de esta investigación de un corpus literario que hace uso de la semiótica para fundamentarse teórica y metodológicamente.

\section{Ideologema}

Un ideologema, en El prestigio de la belleza (Bonnett, 2013), se convierte en una postura ideológica y axiológica que está representada por medio del lenguaje bien sea en un objeto, una frase o un personaje que establece una relación eufórica o disfórica frente a otro ideologema que lucha por legitimarse. El ideologema está presentado por medio del narrador, en este caso, la mujer autobiografiada quien se debate entre dos ideologemas que se hallan en discusión en la esfera sociocultural colombiana, en torno a la representación de la belleza.

El hablante en la novela siempre es, en una $u$ otra medida, un ideólogo, y sus palabras, siempre son ideologemas. Un lenguaje especial en la novela es siempre un punto de vista especial acerca del mundo, un punto de vista que pretende una significación social. Precisamente como ideologema, la palabra se convierte en la novela en objeto de representación. (Bajtín, 1989, p. 150)

\section{Ideologema en la mamá}

La mujer autobiografiada trae a colación, por medio del relato, un fragmento de una cancioncilla que recitaba la mamá en la infancia, la cual es clave para evidenciar el ideologema en la mamá:

Pues yo como soy bonita

con poco estudio tendré,

y de ese modo obtendré

ser una gran señorita. (Bonnett, 2013, p. 18).

En estos versos queda en evidencia el pensamiento del universo sociolectal del relato en el que transcurre la narración $\mathrm{y}$, además, parte de su sistema axiológico. Estos versos causan el efecto de ideología que descubre una forma de vida basada en la facilidad que otorga el tener belleza (Hamon, P., 1984) $\mathrm{y}$, a su vez, propone, indirectamente, una vida llena de obstáculos para aquellos que carecen de ser valorados como bellos según los parámetros de la rejilla de evaluación colectiva ${ }^{1}$.

Metafóricamente, esta situación puede estar representada en la primogénita que se ve en dificultades para salir del vientre materno y entrar al mundo y en la norma evaluante que este universo sociolectal tiene ya planteada, a partir de una axiología y forma de vida compartida. "Cuando mi cabeza empezó a penetrar en el túnel que me conduciría a la salida, me

Anne Paveau afirma que los estereotipos construidos y compartidos culturalmente se convierten en una rejilla de evaluación que condiciona la comprensión del mundo, pues es a través de esta que los elementos culturales y propios de un entorno entran a ejercer el rol que permea la sanción (2006). 
encontré con un obstáculo, el primero de los muchos que iba a tener a lo largo de la vida" (Bonnett, 2013, p. 10). Ese primer obstáculo, de los muchos que se le presentarían (por ser fea), no sería preocupación para su hermana, que tendrá una vida con menos contratiempos, ya que la autobiografiada relata que "[...] mi hermana, con una facilidad pasmosa, sacó su cabeza por el camino ya expedito que yo tan brutalmente había abierto" (2013, p. 12). Esta reafirma a lo largo de la novela, dentro de otras citas, la relación de diferencia entre estas dos hermanas con rasgos figurativos distintos que serán regidas bajo ideologemas distintos.

\section{Ideologema en la niña}

Por su parte, la autobiografiada presenta también un ideologema latente, en ella, en el cual propone que:

Para remediar mi fealdad mi madre recurrió a otros ardides [...] Tomó entonces, apenas pudo, todo tipo de iniciativas, gracias a las cuales mis neuronas fueron bombardeadas con innumerables estímulos: a través de sus axones y dendritas mis células nerviosas recibieron, mucho antes de pisar un colegio, el impacto del Número y de la Letra Escrita $[\ldots]$ la educación era la única forma de salir adelante. (Bonnett, 2013, p. 18)

Contrariamente al primer ideologema en la mamá, la autobiografiada debe optar por la educación y por ser intelectual como única forma de salir adelante, ya que, al menos para ella, el ser bella físicamente no es una opción.

La autobiografiada reconoce en el saber un gran valor que puede ayudar a mitigar sus insatisfacciones y virtualizaciones en programas narrativos anteriores. Este ideologema da paso a toda una reconstrucción discursiva de la belleza, ya no física, sino de la razón y del lenguaje; puesto que a través del saber y del lenguaje se construyen unas representaciones discursivas de la belleza más englobantes, incluso que superan lo corporal.

En otras palabras, el cuadrado semiótico deja ver unas posiciones que se presentan entre formas de vida distintas: una forma de vida basada en la belleza física y otra forma de vida, que se empieza a erigir, en el que la belleza es representada discursivamente como la belleza del intelecto, la creación y la palabra (Burke,1987). En definitiva, se presentan dos posturas ideológicas representadas en la mamá y en la niña como sujetos creados a partir del lenguaje (Van Dijk, T., 1999) para dar cuenta de ideologemas sociales: "La imagen en la novela de tal lenguaje es la imagen de un horizonte social, de un ideologema social unido a su palabra" (Bajtín, 1989, p. 173).

\section{Palabras ideológicas}

Para seguir con el análisis de las posturas ideológicas que se hallan en el relato autobiográfico novelesco, se hace necesario abordar, desde Bajtín, las palabras ideológicas como aquellas que permiten reconocer las fuerzas y la polifonía de voces ideológicas que se esconde en la construcción narrativa en primera persona:

El desarrollo ideológico del proceso de formación se caracteriza precisamente por una divergencia terminante entre esas dos categorías: la palabra autoritaria (religiosa, política, moral la palabra del padre, de los adultos, de los profesores, etc.) carece para la conciencia de convicción intrínseca; y la palabra intrínsecamente convincente, carece de autoridad, no está sostenida por ninguna autoridad, carece con frecuencia de reconocimiento social (de la opinión pública, de la ciencia oficial, de la crítica) y hasta de legitimidad. (Bajtín, 1989, pp. 158-159)

\section{Palabra autoritaria}

La palabra autoritaria es aquella que contiene una carga ideológica y hace parte, se podría decir, de un ideologema que está 
instaurado de antemano en un entorno sociocultural y que asume esa voz, la voz irrefutable, puesto que, es la autoridad contra la cual los sujetos no pueden obrar.

La palabra autoritaria pide ser reconocida y asimilada por nosotros, se nos impone con independencia del grado de persuasión interna de la misma en lo que nos concierne; la encontramos asociada con anterioridad a la autoridad. La palabra autoritaria se encuentra en una zona alejada, orgánicamente ligada al pasado jerárquico. Es, por decirlo así, la palabra de los antepasados (Bajtín, 2013, p. 159

La palabra autoritaria se convierte en esa voz preexistente que se halla investida de autoridad para legitimar o configurar un ideologema, que no está puesta en discusión, es decir, que sencillamente se asume sin lugar a duda.

Esta palabra es impuesta a la autobiografiada por parte de la mamá (de la abuela y de todo el entorno sociocultural) sin persuasión o mayor facilidad de opciones; pues el ser bella ya está constituido y reconocido oficialmente en el pueblo, como una forma de vida. Como mujer, la autobiografiada debe ser bella en su entorno sociocultural, más aún, por el hecho de pertenecer a una familia (medianamente acomodada) que necesita que sus hijas gocen de una buena imagen para perpetuar la belleza generacional y conservar su estatus social en el pueblo, la belleza de estas mujeres es el medio por el cual esta familia consigue buenas alianzas mediante el matrimonio, asimismo, para hacer el menor desgaste intelectual posible, puesto que se obtiene todo mediante la figura de ser bella físicamente $\mathrm{y}$, así, mantener relaciones sociales con gente de prestigio.

Mientras nos miraba, una al lado de la otra, mi madre debió preguntarse secretamente por nuestros destinos. Mi hermana llevaba gran trecho ganado, pues la belleza, bien se sabe, es ganzúa que hace ceder todas las cerraduras. (Bonnett, 2013, p. 13)

El ideal de ser bella para ganar facilidades en el transcurso de la vida se presenta en el relato como una palabra autoritaria que, por su legado histórico, no se refuta; los sujetos que se mueven bajo esta voz autoritaria tienen claro, en su sistema axiológico, que la belleza sirve para abrir puertas en ámbitos sociales, familiares, políticos y económicos. En otras palabras, se hacen evidentes unas representaciones discursivas de la belleza que apuntan a convertir el valor de la belleza en llave maestra de las oportunidades y en el camino fácil para tener una vida cómoda, sobre todo si se es mujer.
La palabra autoritaria pide de nosotros un reconocimiento absoluto, y no una dominación y asimilación libres, con nuestras propias palabras. Por eso no admite ningún tipo de juego en el contexto que la encuadra o en sus fronteras, ningún tipo de transición gradual y lábil, de variaciones estilizantes libres, creadoras. (Bajtín, 1989, p. 160)

El pueblo de la autobiografiada se rige bajo esta palabra autoritaria, la abuela ha educado a generaciones bajo este pilar, la mamá, desde muy niña tiene instaurada esta voz autoritaria en su aparato cognitivo y sistema de valores, es por ello que, se empecina en tener y mantener hijas bellas. Es decir, contra esta palabra legitimada no hay mucho que hacer, pues, al menos para esta sociedad, esa es la palabra que tiene la autoridad, es la que está asimilada, reconocida y aceptada socialmente como parte de un estereotipo construido a través del tiempo, que puede convertirse en una visión sobre valorada, gracias la mirada tradicional y su aparato axiológico.

\section{Palabra intrínsecamente convincente}

La palabra intrínsecamente convincente (como una postura nueva y por qué no revolucionaria) busca entrar en tensión o diálogo con la palabra autorita- 
ria (aquella que se ha posicionado a través del tiempo como legítima y aceptada socialmente) con miras a ganar una aceptación legítima por parte de los sujetos que recurren a ella para dar sentido a su vida. La palabra intrínsecamente convincente, en este caso, provoca un pensamiento independiente $\mathrm{y}$ crítico sobre la voz autoritaria e intransigente de ser bella, que reflexiona sobre el tener privilegios por ser bella o padecer a causa de la fealdad.

En la existencia cotidiana de nuestra conciencia, la palabra intrínsecamente convincente es seminuestra, semiajena. $\mathrm{Su}$ productividad creadora, está precisamente en el hecho de que provoca un pensamiento independiente y una nueva palabra independiente; organiza desde el interior la masa de nuestras palabras, pero sin quedarse en situación de aislamiento o inmovilidad [...] Con todo, no es interpretada por nosotros, sino que se desarrolla libremente todavía más, se adapta a un nuevo material, a nuevas circunstancias, se autoesclarece con nuevos contextos. Más aún, entra en interacción intensa y en lucha con otras palabras intrínsecamente convincentes $[\ldots]$ La estructura semántica de la palabra intrínsecamente convincente, no es acabada, sino abierta; es capaz de descubrir, en cada nuevo contexto dialógico, nuevas posibilidades semánticas. (Bajtín, 2013, p. 162)
La palabra intrínsecamente convincente mantiene así una relación dialógica y abierta, que da lugar a la creación y a la refutación de aquella palabra autoritaria inamovible que permanece estática, indiferentemente de la situación sociocultural y del fenómeno que afecte.

Esta palabra semiajena se materializa, inicialmente, en la palabra ajena, pero al entrar en diálogo con la situación sociocultural y con las otras palabras ajenas, estás construyen una nueva palabra que permite crear o hacer visible una ideología que no había tenido lugar en una situación específica.

La autobiografiada, pese a estar subyugada por la palabra autoritaria, tiene un espacio para entrar en diálogo con la palabra ajena que le muestra o le ayuda a vislumbrar una salida posible al problema de la fealdad:

Qué me hacía indigna de ser amada? Lo primero que se me ocurrió fue mirarme en el espejo. [...] Sí, era fea. Por eso $\mathrm{Lu}$ no podía quererme. Empecé a llorar. [...] Esa noche me acosté pensando qué era yo, más allá de bonita o fea. ¿Simpática, inteligente, buena, culta? [...] ¿Era hora de empezar a construirme un ser, una identidad que hiciera prescindible mi físico? [...] Lo de simpática no había dado buenos resultados. En cuanto a lo demás, se nace con más o menos inteligen- cia, sin remedio. La bondad no me atraía especialmente, y en cambio las personas muy buenas me parecían o sosas o soberbias. Quedaba la alternativa de ser culta, aunque no estaba totalmente segura de que esa fuera razón suficiente para ser querida por alguien. Pero iba a intentarlo. (Bonnett, 2013, pp. 88-89)

El rechazo del otro hacia su ser, la enfrenta a la imposibilidad de ser amada y esto le produce a la autobiografiada una pena enorme que la lleva al llanto y a la desesperación. No obstante, contrariamente al hacer de los personajes femeninos analizados en obras literarias por Harkot de la Taille, la autobiografiada reflexiona sobre las posibilidades que tiene para conjurarse a una buena imagen; por ejemplo, piensa en algunas posibles formas de reconstruir su buena imagen a partir del ser simpática, ser inteligente, ser buena o ser culta. Inmediatamente después de la reflexión, deja claro que se dedicará a emprender una serie de programas narrativos que la lleven a ser culta.

La autobiografiada gracias a sus abundantes lecturas y cercanía con libros de historia, geografía, diccionarios, obras literarias, entre otras producciones, logra construir una voz intrínsecamente convincente, en la que, el ser culta empieza a tomar fuerza, desde una voz semiajena y revolucionaria, y se convierte 
en una voz que dialoga con la voz autoritaria, voz en cual la belleza solo había sido percibida desde los matrimonios por conveniencias y el trampolín a todos los obstáculos de la vida.

La academia y el cuidado de sí desde el intelecto tienen por objeto dotar de competencias al sujeto para que este pueda, por sus propios medios, dar solución al problema de la representación de la belleza corporal.

Esta palabra intrínsecamente convincente, no legitimada, da cuenta de un sistema axiológico en el que lo corporal pasa a un segundo plano; puesto que, el ser culto permite que la palabra, la razón y el intelecto represente discursivamente que, la belleza trasciende de un sujeto que no depende de su figura corporal para gozar de amor, prestigio $\mathrm{y}$ reconocimiento.

Tanto la autobiografiada como la madre tienen en su sistema axiológico instaurado el valor de la dualidad belleza/fealdad; no obstante, por el vertimiento del valor en objetos diferentes se presume que apuntan a formas de vida distanciadas: la autobiografiada, durante sus diferentes etapas, da cuenta de la forma de vida del artista, en tanto la madre opta por seguir una forma de vida fácil para la mujer bella. En los dos casos, se busca mediante una forma de vida (racional) el prestigio, el reconocimiento, el amor y la aceptación en la sociedad.

En definitiva, la autobiografiada descubre, mediante la academia como voz intrínsecamente convincente, una dimensión cultural de la cual carece el entorno en que es socializada, pues la voz autoritaria es la que domina en todos los ámbitos. Es decir, que la narradora-personaje demuestra mediante sus recorridos narrativos que la belleza no concierne meramente al cuerpo, sino que, es necesario cultivar el espíritu para alcanzar este valor. En otras palabras, esta representación discursiva de la belleza abordada desde la niña, la adolescente y la mujer, que es relatada ulteriormente mediante la Mujer autobiografiada, es una apertura al cultivo y al cuidado de sí, para ser autónomo desde la razón, sensible e intelectual.

\section{Géneros intercalados}

"La novela permite la incorporación a su estructura de diferentes géneros, tanto literarios (novelas, piezas, líricas, poemas, escenas dramáticas, etc.), como extraliterarios (costumbristas, retóricos, científicos, religiosos, etc.)" (Bajtín, 1989, p. 138). Estos géneros intercalados conservan su estructura, autonomía y especificidad tanto lingüística como estilística, e incluso, llegan a tener un rol crucial en la estructura de la novela: El prestigio de la belleza intercala la creación autobio- gráfica novelesca con textos poéticos y filosóficos que inciden en la consolidación ideológica de un texto hilado a partir de géneros intercalados.

“Los géneros poéticos en verso (por ejemplo, líricos), intercalados en la novela, pueden ser, desde el punto de vista poético, directamente intencionales, llenos de sentido" (Bajtín, 1989, p. 139). En la autobiografía novelesca en cuestión, se hace uso constante de los géneros intercalados, especialmente, se hace uso de los géneros poéticos para llenar de sentido el enunciado que le precede y decir, mediante los versos intercalados, lo que no dice directamente la autobiografiada.

Por ejemplo, en una parte de la narración se hace uso de algunos versos de Bécquer para dotar de sentido una práctica de escritura que estaba empezando a realizar la autobiografiada como forma de catarsis, como una manera de reconstruir su dignidad como ser humano, como una forma de dar sentido a su existencia:

Abrí, esperando encontrar algún relato, y me encontré con una extrañísima "Introducción sinfónica" que empezaba con estas sugestivas palabras: Por los tenebrosos rincones de mi cerebro acurrucados y desnudos, duermen los extravagantes hijos de mi fantasía esperando en silencio que el Arte los vista 
de la palabra para poderse presentar decentes en la escena del mundo $[\ldots]$ Aunque no era del todo claro, sentí que el texto no solo me estaba hablando en clave sino que había sido escrito para mí $[\ldots]$ Ignoraba que desde ese momento me había convertido en militante de las huestes románticas. (Bonnett, 2013, pp. 114-115)

La autobiografiada trae a colación estos versos porque posiblemente quiere mostrar que es consciente de que solo mediante el cerebro, figura de la razón, del intelecto, del trabajo $\mathrm{y}$ del rigor que puede llegar a despertar sensibilidades con las cuales puede mostrarse en escena (en el mundo), mediante sus productos artísticos, creaciones con la palabra, y ya no mediante su cuerpo. La Mujer está declarando, mediante este género allí intercalado, toda una postura ideológica y el emprendimiento de una lucha que apenas empieza contra esa voz autoritaria y ese ideologema de la madere que se planteó anteriormente.

Otro género intercalado es el texto filosófico, que se hace evidente y que funciona como detonante para la reflexión, que cuestiona la posición de la voz autoritaria como aquella que únicamente ha determinado generacionalmente cómo se es bella y cuáles son los rasgos que favorecen a una mujer en la labor de mantener un prestigio efímero a partir de la belleza corporal:

Unos días más tarde, aprovechando un rato ocioso, mamá fue hasta la pequeña biblioteca, sacó una cartilla y leyó, como si no fuera conmigo: Resulta que Yang-Tsu hizo un viaje al pais Sung y pernoctó en un albergue. El amo del albergue tenía dos mujeres: una era hermosa y la otra fea. La fea era la querida y la hermosa menospreciada. Yang-Tsu preguntó la causa de ello. El amo del albergue le respondió: la guapa se tiene por guapa y yo no la encuentro guapa. La fea se tiene por fea y yo no la encuentro fea. Puedo transcribir la historia porque en mis años universitarios volví a encontrarla y supe que pertenece a la obra de Zhuangzi o Chuang Tzu, un filósofo chino que vivió en el siglo IV antes de Cristo. (Bonnett, 2013, p. 70)

En este caso, se opta por un texto filosófico que se aprovecha dentro de la novela para generar un cuestionamiento indirecto sobre aquella voz autoritaria (y sistema axiológico que soporta el mundo tradicional de la autobiografía) que no está dispuesta a entrar en discusión sobre los parámetros figurativos de la mujer bella. En otras palabras, este fragmento filosófico, que pone en evidencia un problema alrededor de la representación de la belleza desde hace siglos, se convierte en una forma de interpelar a aquella voz autoritaria y aquel ideologema que se defiende a partir de la visión de la madre, la abuela y el pueblo en general; con el fin de generar y permitir un diálogo en el que se escuche también la voz ajena, la semiajena y la intrínsecamente convincente.

\section{Polifonía}

La polifonía es una condición de existencia para el dialogismo, en la que existen diferentes voces en un texto (Goldmann et al., 1969), pero no cualquier tipo de voces. Bajtín se refiere a unas voces ideológicas que permitan discutir, por ejemplo, una postura estética desde la objetividad del consenso social o desde la intersubjetividad de un grupo que se ve afectado por la primera.

La objetividad estética como parte de una voz autoritaria, según Mandoki (2006b), lo mismo que para otros investigadores de las ciencias sociales y de la semiótica como Peirce (1978), Greimas (1989), Fontanille (2013), Restrepo, M. (1993) y Eco (2008), entre otros, no es otra cosa que la incorporación, en el aparato cognitivo personal, de un consenso entre diversos sujetos en el entorno social y cultural. Este consenso, que se traduce en un modelo cognitivo, es un paradigma para interpretar los fenómenos de la percepción, la valoración y significación de la 
belleza que termina por convertirse en un fetiche estético compartido culturalmente. Sin embargo, la autobiografiada deja el estado de enajenación inicial, para comenzar a percibir los objetos del mundo desde una perspectiva diferente, que le permite valorar estéticamente los fenómenos a partir de otro punto de vista, libre de mitos y miedos, gracias a la intervención del saber y la academia. Es decir, se da lugar a una voz intrínsecamente convincente que entra a dialogar con la voz autoritaria.

En otras palabras, la Mujer de la obra analizada abre un camino de conjunción con otra forma de belleza y eso le permite constituirse en un sujeto que se autodetermina y que escapa al fetiche social (para entrar en otro, posiblemente) gracias a la polifonía de voces ideológicas que dialogan en la narración.En definitiva, en la novela objeto de análisis se halla una polifonía de voces que expresan su acuerdo o desacuerdo con una postura estética y forma de vida mediante la voz autoritaria o la palabra intrínsecamente convincente presente en el texto, que siguen allí para problematizar sobre una representación discursiva de la belleza desde la mirada tradicional o desde la construcción del intelecto que, más allá de querer tener un prestigio efímero (desvaneciéndose en el tiempo y desapareciendo), apuntan a un prestigio logrado por la capacidad de crear obras artísticas y mantener el ejercicio del intelecto como una opción más trascendente frente a lo efímero de una belleza corporal.

\section{Dialogismo (interno)}

El dialogismo, según la bajtinología es la relación entre esas voces polifónicas que resuenan en el texto literario y permiten la comunicación entre una postura ideológica y otra. "El dialogismo interno de la palabra es un acompañante indispensable de la estratificación del lenguaje, una consecuencia de estar superpoblado de intenciones plurilingües" (Bajtín, 1989, p. 147). Algunos personajes o grupo de personajes se conciben como voces ideológicas en el relato. En la biografía novelesca que se estudia, se puede percibir esa relación de voces en diálogo, por medio del sistema de personajes que se plantea en el relato de la autobiografiada.

En el sistema de personajes, de El prestigio de la belleza, se halla inicialmente la figura de la madre, este se construye en el enunciado como un personaje colectivo, por medio del cual se percibe el pensamiento de todo un grupo social. La mamá como personaje, portador de una voz, se configura mediante como la voz autoritaria en la idea del ser bella y mantiene en el relato un discurso que defiende y reafirma esta posición:
Fue así como se dedicó a frotar mi tabique con manteca de cacao, a peinarme con agua de linaza y de manzanilla, a embadurnar la mancha de mi labio con un pegote de concha de nácar, a darme leche en cantidades colosales para dotar de calcio mis huesos [...] yo fui así altar, tótem, pastel, objeto sagrado frente al que mi madre se doblegaba con reverencia mientras untaba sus sales y sus bálsamos. (Bonnett, 2013, p. 13)

Por su parte, la autobiografiada opta por un ser intelectual, que está allí para cuestionar a la voz autoritaria y entrar en dialogismo, con el fin representar discursivamente la belleza en otros significados diferentes al cuerpo y poder forjar otro camino para gozar de prestigio social, como parte de una identidad narrativa construida lingüísticamente:

Mi enamoramiento, entonces, cambió de curso: ya no se dirigió a un ser humano, por demás inasible $-\mathrm{y}$ con toda seguridad insignificante-, sino a la lengua. Me obsesioné con ella, me sumergí en sus cauces, engullí cada una de las palabras aprendidas como atragantándome de maravillosos caramelos. Steiner habla del "esplendor verbal" del francés y dice que hasta "las necrológicas francesas pueden ser locuaces". Mi propia locuacidad empató con la de aquella lengua rumorosa, hasta el punto de hacerme sentir que yo había nacido con una nacionalidad y un idioma equivocados. (Bonnett, 2013, p. 99) 


\section{Conclusiones}

Concluyentemente, en el sistema de personajes se presenta una heterofonía que corresponde al ser bella y al ser intelectual como formas de vida que proporcionan prestigio, reconocimiento, amor y felicidad.
Ahora queda todo un camino por explorar de la mano con la bajtinología, pues, como se ha demostrado en estos pocos ejemplos, los conceptos teóricos que propone Bajtín, y que han sido retomados por otros estudiosos de la literatura, siguen estando vigentes para aná- lisis semióticos en textos literarios que permiten la reflexión y la comprensión profunda de los textos de la cultura (Courtés, J., 1997), donde la mujer tiene un papel trascendental, especialmente en la literatura colombiana.

\section{Referencias}

Alberca, M. (1999). En las fronteras de la autobiografía. En M. Ledesma Pedraza (ed.), Escritura autobiográfica y géneros literarios (pp. ). Jaén, España: Universidad de Jaén.

Bajtín, M. (1989). Teoría y estética de la novela. Trad. Helena Kriúkova y Vicete Cazcarra. Madrid: Taurus.

Bonnett, P. (2013). El prestigio de la belleza. Bogotá: Alfaguara.

Burke, E. (1987). Indagación filosófica sobre el origen de nuestras ideas acerca de lo sublime y de lo bello. Madrid: Editorial Tecnos.

Courtés, J. (1997). Análisis semiótico del discurso. Del enunciado a la enunciación. Madrid: Gredos.

Eco, U. (2008). Historia de la belleza (9a ed.). Barcelona: Lumen.

Fontanille, J. (2013). Medios, regímenes de creencia y formas de vida. Contratexto, (21), 65-82. Recuperado de http:/www1.ulima.edu.pe/Revistas/contratexto/v21/04\%20-\%2021.pdf

GOLDMANN, L. y BARTHES, Roland (compiladores). (1969). Literatura y sociedad. Problemas de la metodología en sociología de la literatura. Barcelona: Martínez Roca.

Greimas, A. J. (1989). Del sentido II. Ensayos semióticos. Madrid: Gredos.

Hamon, P. (1984). Texte et idéologie. Valeurs, hiérarchies et évaluations dans l'ouvre littéraire Paris: Presses Universitaires de France.

LONDOÑO, V. Patricia, JURSICH, D. Mario. (1995) Diarios, memorias y autobiografías en Colombia. En: Boletín Cultural y Bibliográfico, Vol. 32, no. 40, pp. 142-162. 
Mandoki, K. (2006a). Estética cotidiana y juegos de la cultura. Prosaica I. México: Siglo xxi Editores.

Mandoki, K. (2006b). Prácticas estéticas e identidades sociales. Prosaica II. México: Siglo Xxı Editores.

Paveau, M. A. (2006). Les prédiscours. Sens, mémoire, cognition. París: Presses Sorbonne Nouvelle.

PEIRCE, Charles. (1978) Écrits sur le signe. Paris: Le Seuil. Precedida por la numeración de la edición de Cambridge (PEIRCE Charles. Collected papers. Cambridge (Mass.): Charles Hartshorne \& Paul Weiss, Harvard University Press, 1931-1935 \& 1957-1958. vol. 2).

Restrepo, M. (1993). Ser-signo-interpretante. Bogotá: Significantes de Papel Ediciones,

Romera, J. (1981). La literatura, signo autobiográfico (el escritor signo referencial de su escritura). En J. Romera (ed.), La literatura como signo (pp. 13-46). Madrid: Playor.

Van Dijk, T. (1999). Ideología. Una aproximación multidisciplinaria. Trad. Lucrecia Berrone de Blanco. Buenos Aires: Gedisa.

\section{ARTÍCULOS RECOMENDADOS}

Motato Camelo, H. (julio-diciembre de 2013). De la casa al universo en la poesía de Piedad Bonnett Vélez. La Palabra, (23), 33-48.

Pinzón Manrique, H. J. (enero-junio de 2014). La literatura como in-corporación: el cuerpo como proceso. La Palabra, (24), 91-97. 